\title{
Resolution of MRI findings of copper deficiency myeloneuropathy in a patient with Wilson's disease
}

Resolução dos achados de RNM em paciente com doença de Wilson que desenvolveu mieloneuropatia por deficiência de cobre

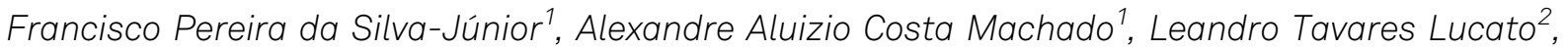
Egberto Reis Barbosa ${ }^{1}$

We have previously described the case of a patient with Wilson's disease who developed copper deficiency myeloneuropathy $(\mathrm{CDM})^{1,2}$. One year after zinc withdrawal, mild improvement of sensory symptoms was reported, with unchanged neurologic examination. Urinary copper excretion has increased from 7.4 to $80 \mu \mathrm{g} / 24$ hours and serum zinc level has decreased from 311 to $106 \mu \mathrm{g} / \mathrm{dL}$. Resolution of MRI findings was observed (Figure). She remains on regular

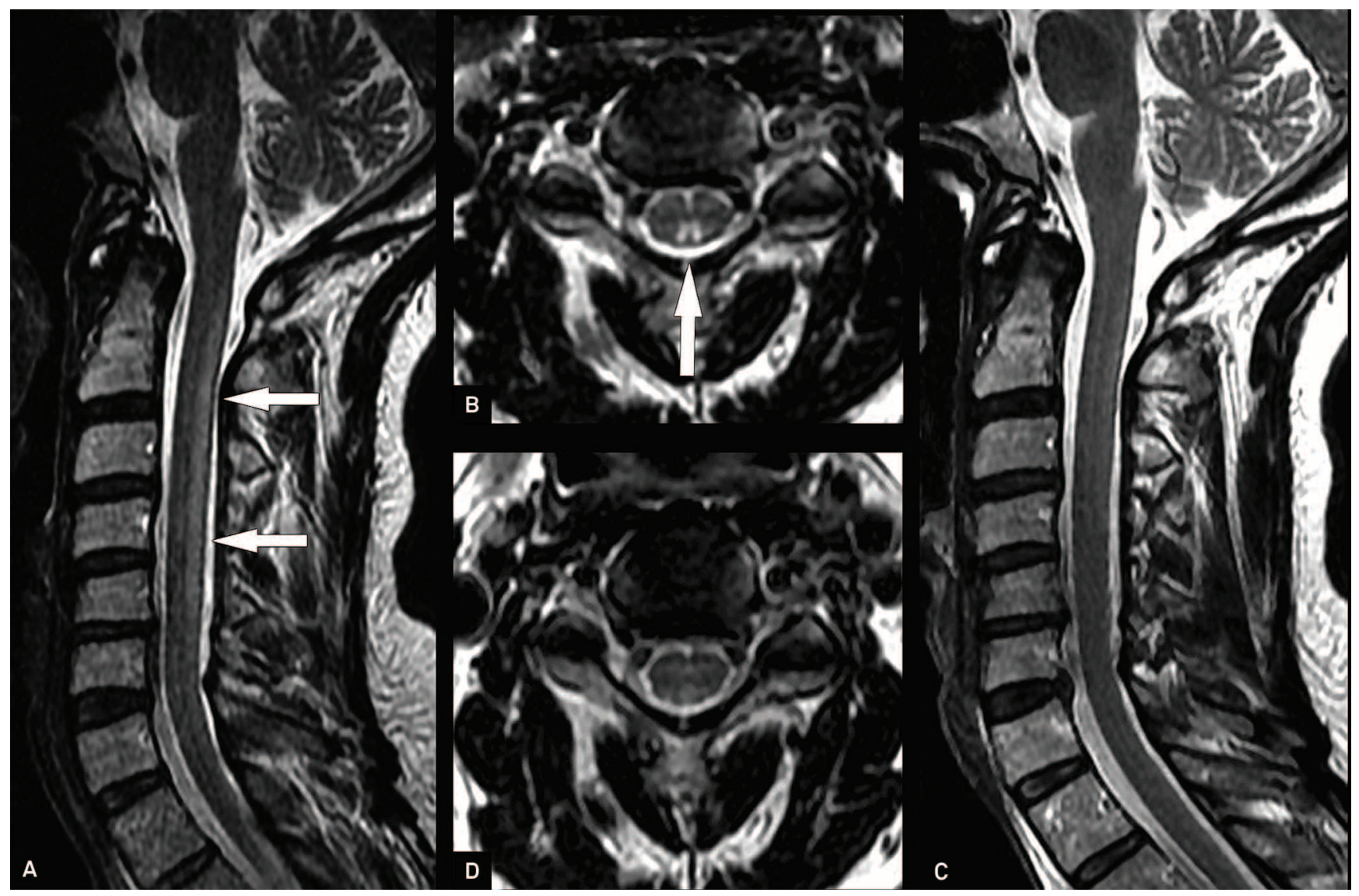

Figure. Initial sagittal (A); axial (B); $T_{2}$-weighted images of the cervical spine demonstrate bilateral and symmetric hyperintense lesions involving the dorsal columns of the cervical spinal cord, extending from $\mathrm{C}_{1}$ to $\mathrm{C}_{6}$ (arrows); one-year follow-up exam discloses resolution of the lesions in the sagittal (C); axial (D); $T_{2}$-weighted images.

${ }^{1}$ Departamento de Neurologia, Universidade de São Paulo, Sao Paulo SP, Brazil ${ }^{2}$ Departamento de Radiologia, Universidade de São Paulo, Sao Paulo SP, Brazil.

Correspondence: Francisco Pereira da Silva-Júnior; Rua Doutor Melo Alves 55 apto 123; 01417-010 São Paulo SP - Brasil; E-mail: franciscops@hotmail.com Conflict of interest: There is no conflict of interest to declare.

Received 15 October 2013; Accepted 22 October 2013. 
clinical monitoring. These results indicate that zinc withdrawal, progression in our patient. Early diagnosis and management of without copper supplementation, was enough to prevent CDM CDM probably have accounted for this satisfactory outcome.

\section{References}

1. da Silva-Júnior FP, Machado AA, Lucato LT, Cançado EL, Barbosa ER.

Copper deficiency myeloneuropathy in a patient with Wilson disease. Neurology 2011;76:1673-1674
2. da Silva-Júnior FP, Lucato LT, Machado AA, Barbosa ER. Copper deficiency in Wilson's disease: an avoidable complication of treatment. Mov Disord 2011;26:2448-2449. 